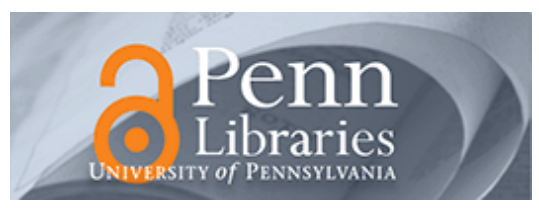

University of Pennsylvania ScholarlyCommons

\title{
The Future of Political Communication Research: Reflections on the Occasion of Steve Chaffee's Retirement from Stanford University
}

Diana Mutz

Annenberg School for Communication, mutz@upenn.edu

Follow this and additional works at: https://repository.upenn.edu/asc_papers

Part of the Communication Commons

\section{Recommended Citation}

Mutz, D. (2001). The Future of Political Communication Research: Reflections on the Occasion of Steve Chaffee's Retirement from Stanford University. Political Communication, 18 231-236. https://doi.org/ 10.1080/105846001750323005

At the time of this publishing, Dr. Diana Mutz was Professor of Political Science, and Journalism and Communication, at Ohio State University.

This paper is posted at ScholarlyCommons. https://repository.upenn.edu/asc_papers/627

For more information, please contact repository@pobox.upenn.edu. 
The Future of Political Communication Research: Reflections on the Occasion of Steve Chaffee's Retirement from Stanford University

\section{Disciplines}

Communication | Social and Behavioral Sciences

\section{Comments}

At the time of this publishing, Dr. Diana Mutz was Professor of Political Science, and Journalism and Communication, at Ohio State University. 


\title{
The Future of Political Communication Research: Reflections on the Occasion of Steve Chaffee's Retirement from Stanford University
}

\author{
Diana Mutz
}

In response to the theme of today's panel, I have outlined just a few of many changes in the nature of the work that we do that are either currently on the horizon or already in progress. These are ways that the study of political communication today strikes me as quite different from when I was being trained as a graduate student of Steve's more than 10 years ago. Many of the issues and questions I pose here also form the bulk of my own "to-do" list with respect to areas where I think our field is in need of further research.

\section{Redefining the Content of Political Communication}

First, we are in a period where we are redefining what is "political" and what it is that we, as political communication researchers, study. It was once the case that what was considered political by political communication researchers could be pretty safely defined as whatever was on the evening news or in newspapers or perhaps in political ads or debates. The places where researchers interested in political communication effects looked for the substance of their independent variables were narrow and well circumscribed. But now that the presidential candidates are on "Oprah" and late-night television programs, things are not so simple. What citizens call "news" now covers dozens of channels and many programs that are not ostensibly news programs, and political views are espoused even in such unlikely places as "Iron Chef" on the Food Network. Thus, the traditional distinctions between news and entertainment content are no longer very helpful.

These kinds of changes in the political information environment should lead to a broadening of our definitions of what is considered political communication. To be sure, there has always been political content in contexts other than the evening news, but in the past we have often conveniently ceded that area of study to scholars in other subfields or other disciplines (see, e.g., Gamson, 1998). I don't think we can afford to do that any longer. Too large a proportion of the political information environment is now outside of these traditional political communication forums.

It is interesting to me to note this development in retrospect because I can recall that even back when I was in graduate school, critical scholars often criticized this very aspect of empirical work on political communication, that is, the overly narrow definition of what was considered "political." I think that criticism now rings especially true. So in response to the question "What do we as political communication researchers study?" the answer that used to be television news, newspapers, debates, and ads should now include far more than that.

\section{Citizens as Active Information Gatherers}

Second, I think political communication research will and should go the direction of a re-emphasis on conceptualization of the citizen as active gatherer and processor of information. The research of the past 10 to 20 years has attempted to answer questions such as "Do political ads influence people's political opinions or behaviors?," "How does watching the evening news change their perceptions of what is important in the political world?," and so forth. Although these certainly remain very important questions, I think we will be seeing a greater emphasis on what leads people to various media as opposed to taking the content as given and studying strictly its effects.

The key reason this will occur is because the emphasis in today's communication environment is on choice, on making it easier for the consumer to get what he or she wants when he or she wants it. We can see this in the proliferation of television channels and the greater number of news programs that are already in existence. But we can also see this potential in technologies like TIVO and Replay that allow us to control not only what we watch but also when we watch it. The capabilities of the Internet have also brought the issue of choice to the fore with its ability to tailor what we see based on what is already known about us. When I log onto Amazon.com, it shows me books that should interest me based on my past purchasing behavior. And although I hate to admit it, they usually 
do. Likewise, newspapers of the future may enable citizens to actively screen out content that does not jibe with their interests and prejudices, thus producing news that has been dubbed The Daily Me (Negroponte, 1995).

This theme - the emphasis on citizens as active processors of information rather than mere passive recipients - is really an old one in communication research. For example, the uses and gratifications tradition more or less defined itself in terms of the study of why people use various sources of information and how their personal motives influence what they get out of it and how it affects them (see Blumler \& Katz, 1974; McQuail, 1984). But this approach is not receiving a great deal of attention these days, at least not within political communication circles. Although research has continued apace in understanding related processes such as selective attention, exposure is less well understood.

Thus, a second older concept that should also experience a research renaissance as a result of the current emphasis on choice is selective exposure. Understanding the extent to which political information choice is selective and on what bases people are selecting sources of political information is going to be a critical part of understanding the implications of the choices that are offered by new media. Many fear that the Internet will make it possible for people to read a daily newspaper tailored to their own particular interests and biases. A recent perusal of the psychology, communication, and political science journal databases suggests that selective exposure is a very quiet area of research at the moment. This should change, at least in part because of the trend toward greater consumer choice in political news.

When research on selective exposure died out, it was far from a settled question. Researchers never reached very satisfying or consistent conclusions about when or under what conditions people sought congenial information or information about those with views different from their own (e.g., Frey, 1986). Many of these experimental studies are also very limited in what they can tell us about life outside the laboratory, where people are not always forewarned about the political content of a given message before exposure, and where use of a particular medium is more of a habitual behavior than a choice made on a story-by-story basis (see Mutz \& Martin, in press).

As choice is made easier for consumers, it raises a host of new theoretical issues for us to grapple with as well. For so long now, the concern in political communication circles has been about the lack of choice in political news. This perspective stemmed from concerns about trends in newspaper ownership, in particular, and the fact that so many U.S. cities and towns became one-newspaper towns during the last century. If you read a local daily as most people did, you typically had no choice as to which newspaper you read. Moreover, most daily newspapers were owned by a relatively small number of large corporations. Thus, the presence of a one-town, one-voice system of reporting political news, in a country with tremendous concentration of ownership, raised the specter of hegemonic control of political information. Interestingly, this situation has not changed for the better; we still have tremendous concentration of ownership, yet very few people these days are complaining about the lack of choice in news sources. Instead, they complain about the proliferation of sources and the lack of a common understanding of public affairs, the kind of understanding that might create opportunities for political conversations in particular (e.g., Katz, 1996). It is interesting to me that in so many public policy arenas these days, we have debates over the merits of choice and what the end results will be of giving people choices. There are endless debates over the consequences of school choice, for example. But in political communication research the debate over the merits of choice has never been fully hashed out. As the number of potential places to obtain news multiplies and consumers must choose among them, that exercise of choice may lead to less diversity of political exposure for any given individual, and it may maximize diversity between individuals. This trend is exacerbated by the fact that advertisers and media firms are now working together toward the creation of "electronic equivalents of gated communities" (Turow, 1997, pp. 2-3). As Turow (1997) has pointed out in his recent book titled Breaking Up America, although the market segments advertisers identify are not explicitly based on political views, their "lifestyle" categories are hardly independent of political leanings. He suggests that "segment-making media" - those that "encourage small slices of society to talk to themselves" - are on the rise, while "society-making media" - "those that have the potential to get all those segments to talk to each other" are on the downslide. 
Trends of this kind obviously reduce the amount of exposure to dissonant views people will receive through media; moreover, specialized media and fragmented audiences may have secondary effects on interpersonal political communication since the experience of shared viewing or reading often provides fuel for conversations across partisan lines.

\section{Effects of New Technology on Social Life}

The third observation I would like to make concerns the political effects of both old and new communication technologies on social life more generally. Themes related to social identity and social interaction are pervasive in the contemporary social science literatures; through concepts such as social capital, characteristics of social life have become linked to a country's political health. When the theme involves effects of communication technologies, it usually takes on an ominous tone. Like virtually every new communication technology before it, the initial reaction to the Internet has been neatly cast in the mass society mold. Fill in the blank with your favorite new communication technology - the Internet or television before it or motion pictures before that. The first hypothesis is that this medium must be causing atomization, alienation, and isolation of the citizen from his fellow man. We've all heard this argument before. Second, the new medium must be causing the breakdown of primary groups by supplanting them with impersonal associations. Finally, this medium must also be responsible for the degradation of social norms. My point is not that such hypotheses are never true; on the contrary, these remain very important research questions. But from the perspective of political communication research, we need to be aware of the assumptions underlying such assertions.

In particular, these theories reflect continued use of face-to-face political communication as the gold standard in political communication research. This is something that Steve Chaffee's research as well as Michel Schudson's work has addressed at some length (e.g., Chaffee, 1982; Chaffee \& Mutz, 1988; Schudson, 1982). For what seems like virtually the entire history of political communication research, every new medium has been compared to interpersonal communication, with the assumption that face-to-face political communication is the ideal mode for the transmission of political information. This kind of thinking pervades the current emphasis on town meetings, on encouraging deliberative democracy, and so forth.

In an ideal world, so the theory goes, not only would people talk politics with one another, all of the candidates could talk one-on-one with citizens individually, and then all would be right with the political world. Whether stated explicitly or not, this is the underlying logic of so much of what was written about television's impact on politics, and I see the same thing emerging with respect to political communication via the Internet.

While I am certain that interpersonal communication must have been one of the earliest forms of political communication, I am not convinced that lengthy heritage makes it the best. Nor has the superiority of interpersonal communication always been the received wisdom for how political communication should ideally take place. For example, when America's founders were debating how to organize government in documents such as the Federalist papers, they were very wary of the power of interpersonal influence and of normative social pressure in particular. Rather than lament the fact that the country was too big to have a town meeting, their hope was that the sheer size of the country would help prevent interpersonal ties from having an impact on people's candidate preferences. The principle of extended sphere was offered as a safeguard against interpersonal influence. If elections were held over a large enough region, the founders reasoned, then it would be difficult if not impossible for candidates to communicate interpersonally with a large number of their constituents. And that was deemed the preferable scenario (see, e.g., Ceaser, 1979). Instead of face-to-face knowledge, they hoped people would vote on the basis of more impersonal information such as the person's reputation.

I have suggested that face-to-face communication should not be accepted uncritically as the ideal type, but why not? Some of the recent critiques of efforts to promote deliberative democracy and face-to-face political discussion have pointed to some of the pitfalls of encouraging democracy through deliberation in settings that seldom meet the standards set by deliberative theory (e.g., Hibbing \& Theiss-Morse, in press; Sanders, 1997). 
In addition, recent studies of Internet communication by people like McKenna and Bargh (2000) begin to give us a more balanced perspective on both the strengths and weaknesses of this unique mode of communication. Their work addresses the capacity for the Internet to allow people to try on various identities and roles. The fact that the Internet strips people of many features known to be tied to identity and credibility has important consequences for political communication. When I was in graduate school, the New Yorker carried a wonderful cartoon featuring a dog in front of a computer terminal, with the dog saying "On the Internet no one knows you're a dog." And of course, it is absolutely true. Features of physical appearance that prompt stereotyping behavior and the discounting of information from sources that are traditionally granted less credibility are all notably absent on the Internet. On the Internet you're not Black or White, young or old, male or female. On the positive side, this kind of anonymity can prompt something closer to what political theorists have in mind when they talk about deliberation, a situation in which views can be exchanged and arguments are evaluated based on their own merits rather than based on cues related to the person's status, cues such as class, race, or gender. In addition, the anxiety over political confrontation that drives so many people away from talking about anything potentially controversial may be lessened on the Internet. Controversy may be a lot less threatening when the people involved are not likely to be part of each other's face-to-face lives, and when the exchange will not take place in person. This characteristic could be advantageous for public discourse.

Finally, I think the Internet also has interesting and important implications for social trust, a concept that has become a small cottage industry in political communication lately. Particularly for the huge portion of the Internet that involves commercial transactions, the development of the kind of trust that is necessary to engage in monetary transactions with distant strangers is essential to the development of the Internet economy. Although by now Americans have long been comfortable with catalog sales involving economic exchange with distant merchants, historians have documented how this trust had to be carefully cultivated by these pioneers in the business world (e.g., Arena, 1995; Boorstin, 1973). Likewise, Internet commerce is prompting the development of alternative means of cultivating trust across the Internet (e.g., Camp, 2000). I recently bought a new car on the Web because it was thousands of dollars less than buying it from a local dealer. I had purchased items on the Web before, but nothing of this magnitude. And it crossed my mind more than once after sending off a large deposit to an address in some small town I had never heard of: What made me think that a car was really going to show up two months later? How did I know I could trust these unknown, unheard of strangers not to pocket my check and disappear? When, a few months later, I made an offer on a house I found on the Web from 2,000 miles away, I found myself once again questioning how much to trust these unknown, unseen others and the representations they offered.

In the future we need to think about social trust in terms that more closely relate to how people interact with one another in the real world, and the kinds of actions they take that require trust outside of immediate friends and family. The new systems that are developing for maintaining identity and reputation and for assessing credibility through remote means are extremely interesting from a communication perspective. For example, EBAY's system is one in which buyers and sellers provide positive and negative feedback about one another, and this designation appears next to a person's identity any time they attempt to engage in a transaction. This system is interesting because it mirrors much older systems for enforcing social norms through public humiliation (e.g., NoelleNeumann, 1984). It also bears similarities to the development of the credit system in the United States, but it is based on public opinion as a means of enforcing responsible behavior rather than a bank statement.

As political information proliferates on the Web, I suspect that similar systems for assessing the accuracy and partisanship of information will develop as well. Although it is far too early to predict whether these changes will bode well or ill for various aspects of the American political system, my level of social trust has been at least temporarily buoyed by the fact that the car arrived as promised, and the house is still standing.

\section{References}

Arena, J. (1995, May). The information society under construction: Retail credit and the discourse of technology. Paper presented at the meeting of the American Association for Public Opinion Research, Fort Lauderdale, FL.

Blumler, J. G., \& Katz, E. (Eds.). (1974). The uses of mass communications: Current perspectives on gratifications research. Beverly Hills, CA: Sage. 
Boorstin, D. J. (1973). The Americans: The democratic experience. New York: Random House.

Camp, L. J. (2000). Trust and risk in Internet commerce. Cambridge, MA: MIT Press.

Ceaser, J. W. (1979). Presidential selection: Theory and development. Princeton, NJ: Princeton University Press.

Chaffee, S. H. (1982). Mass media and interpersonal channels: Competitive, convergent or complementary? In G. Gumpert \& R. Cathcart (Eds.), Inter/Media: Interpersonal communication in a media world (2nd ed., pp. 57-77). New York: Oxford University Press.

Chaffee, S. H., \& Mutz, D. C. (1988). Comparing mediated and interpersonal communication data. In R. P. Hawkins, J. M.

Wiemann, \& S. Pingree (Eds.), Advancing communications science: Merging mass and interpersonal processes (pp. 19-43). New York: Oxford University Press.

Frey, D. (1986). Recent research on selective exposure to information. In L. Berkowitz (Ed.), Advances in experimental social psychology (pp. 41-80). New York: Academic Press.

Gamson, J. (1998). Freaks talk back: Tabloid talk shows and sexual nonconformity. Chicago: University of Chicago Press. Hibbing, J. R., \& Theiss-Morse, E. (in press). Stealth democracy: Americans' beliefs about how government should work. New York: Cambridge University Press.

Katz, E. (1996). And deliver us from segmentation. Annals of the American Academy of Political and Social Science, 546, 22-33. McKenna, K. Y. A., \& Bargh, J. A. (2000). Plan 9 from cyberspace: The implications of the Internet for personality and social psychology. Personality and Social Psychology Review, 4, 57-75.

McQuail, D. (1984). With the benefit of hindsight: Reflections on uses and gratifications research. Critical Studies in Mass Communication, 2, 177-193.

Mutz, D. C., \& Martin, P. S. (in press). Facilitating communication across lines of difference: The role of mass media. American Political Science Review.

Negroponte, N. (1995). Being digital. New York: Knopf.

Noelle-Neumann, E. (1984). The spiral of silence: Public opinion-Our social skin. Chicago: University of Chicago Press. Sanders, L. (1997). Against deliberation. Political Theory, 25, 347-376.

Schudson, M. (1982). The ideal of conversation in the study of mass media. In G. Gumpert \& R. Cathcart (Eds.), Inter/Media: Interpersonal communication in a media world (2nd ed., pp. 41-48). New York: Oxford University Press.

Turow, J. (1997). Breaking up America: Advertisers and the new media world. Chicago: University of Chicago Press.

Note:

Diana C. Mutz is Professor of Political Science, and Journalism and Communication, at Ohio State University.

Address correspondence to Diana C. Mutz, Department of Political Science, Ohio State University, 2140 Derby Hall, 154 North Oval Mall, Columbus, OH 43210-1373, USA. E-mail: mutz.1@osu.edu 